\title{
EL TRABAJO CON LA ACTITUD ESPERANZADA, COMO ACTITUD ÉTICA, DESDE LA PSICOTERAPIA INTEGRADORA HUMANISTA
}

\section{WORK WITH HOPEFUL ATTITUDE FROM INTEGRATIVE HUMANISTIC PSYCHOTHERAPY}

\section{Miquel Francesc Oriol Guerrero}

Instituto Erich Fromm de Psicoterapia Integradora Humanista y Centro de Psicoterapia Integrador

Cognitivo-Humanista, Barcelona, España

Cómo referenciar este artículo/How to reference this article:

Oriol Guerrero, M.F. (2017). El trabajo con la Actitud Esperanzada, como Actitud Ética, desde la Psicoterapia Integradora Humanista. Revista de Psicoterapia, 28(107), 155-174.

\section{Resumen}

La esperanza es reconocida como unos de los cuatro factores que contribuyen al cambio psicoterapéutico, y que es transversal a los diferentes enfoques de la psicoterapia. Asimismo, es indudable su importancia en el desarrollo ético de la personalidad. Sin embargo, no es abundante la literatura sobre la aplicación de intervenciones clínicas especificas para su tratamiento durante el proceso psicoterapéutico. En todo caso, existen aproximaciones desde enfoques cognitivos, en los que las dimensiones emocional y ética de la esperanza reciben una atención residual. Este artículo pretende mostrar algunas intervenciones desde el modelo de la Psicoterapia Integradora Humanista (PIH), modelo creado en los años 80 en el Instituto Erich Fromm de Barcelona por Gimeno-Bayóny Rosal (2016, 2017).

Palabras clave: Esperanza, ética, Psicoterapia Integradora Humanista, intervención

\begin{abstract}
Hope is recognized as one of the four factors that contribute to psychotherapeutic change, and which is transversal to the different approaches of psychotherapy. Also, its importance in the ethical development of the personality is undoubted. However, the literature on the application of specific clinical interventions for its treatment during the psychotherapeutic process is not abundant. In any case, there are approximations from cognitive approaches, in which the emotional and ethical dimensions of hope receive residual attention. This article aims to show some interventions from the model of Humanistic Integrative Psychotherapy (PIH), a model created in the 80 s at the Erich Fromm Institute in Barcelona by Gimeno-Bayón and Rosal (2016, 2017).

Keywords: Hope, ethics, Integrative Psychotherapy Humanist, intervention
\end{abstract}




\section{Introducción}

A pesar de que la esperanza ha sido reconocida como uno de los cuatro factores implicados en el cambio terapéutico, independientemente del enfoque del proceso de la psicoterapia (Hubble, Duncan, \&Miller, 1999), y que, en los últimos 30 años ha aumentado la literatura e investigación sobre la misma, pocos son los estudios sobre aplicaciones y/o intervenciones clínicas de la misma (Larsen, Edey \& LeMay, 2007). Entre estos, encontramos los estudios derivados de la Hope Theory (Snyder, Rand \& Sigmon, 2002) y (Cheavens, Feldman, Gum, Michael \& Snyder, 2006) desde una conceptualización básicamente cognitiva de la esperanza. Así, el tratamiento se centra en: proponerse objetivos con sentido y realizables, desarrollar diferentes maneras de trabajar hacia esos objetivos pathways thinking, identificar fuentes de motivación o controlar las fuentes de desmotivación agency thinking , monitorizar el proceso y , por último cambiar de metas/objetivos goals si es necesario. Desde esta teoría, las emociones negativas (desagradables) serían un producto de los pensamientos negativos ante las dificultades o fracasos en conseguir dichos objetivos (Snyder, 2005). Por otra parte, los estudios de Larsen y Stege (2010a, 2010b) se centraron en el uso implícito/explícito de la esperanza en las tres primeras sesiones de terapia y su impacto en el proceso. Entienden como uso implícito aquel que se hace sin nombrar a la esperanza: a un primer nivel de relación terapéutica, escuchando y sosteniendo el relato de desesperanza del cliente y señalando sus recursos después. Por otra parte, generando nuevas perspectivas del problema, a través de metáforas, reencuadre, compartiendo historias o con el uso de la externalización y/o el humor.

A nivel explícito se investigó el uso del término esperanza en sus dimensiones cognitivas, conductuales, emocionales, relacionales y temporales. Siempre a través del lenguaje, del discurso, de la conversación con el cliente.

No se han encontrado intervenciones desde lo psicocorporal o desde la fantasía, acercamientos propios del movimiento psicológico-humanista, ni tampoco ninguna mención a la dimensión ética de la esperanza.

Como puede observarse, la investigación sobre la aplicación de intervenciones para incrementar la esperanza se encuentra en su fase inicial. Este artículo pretende mostrar y describir una serie de intervenciones desde un modelo humanista, holístico e integrador: la Psicoterapia Integradora Humanista. No obstante, y cómo puede observarse en las diferencias entre los estudios señalados anteriormente, el campo que se propone explorar es muy amplio y requiere, por tanto, una primera ubicación y delimitación tanto del objeto de estudio, la esperanza, cómo de las teorías y modelos desde los que la exploramos. ¿ A qué se llama esperanza? ¿Cómo se justifica la esperanza cómo actitud ética? ¿Cómo operativizar dicho concepto? ¿Qué es la Psicoterapia Integradora Humanista? ¿Cómo se justifican las intervenciones desde dicho modelo psicoterapéutico? Preguntas pertinentes a las que se intentará responder en los siguientes apartados del artículo. Tras dichas justificaciones y marcos explicativos y descriptivos, se pasará de lo general a lo 
particular, mostrando la descripción de algunas intervenciones realizadas, desde el modelo de la Psicoterapia Integradora Humanista, en un caso clínico.

\section{¿A qué se llamará esperanza en este estudio?}

Varias son las definiciones y acepciones del concepto esperanza: desde la de un estado de ánimo: "estado del ánimo en el cual se nos presenta como posible lo que deseamos" (RAE, 2014), pasando por una acepción emocional: "Emoción compleja afín a la emoción de alegría "(Greenberg, 2000). Otros autores, han puesto el acento en lo cognitivo del concepto:

Un proceso cognitivo que cuenta con tres componentes:

a) establecimiento de objetivos.

b) capacidad para el desarrollo de diferentes vias (cognitivas) para alcanzar dichos objetivos.

c) habilidades para mantener la motivación en el proceso (Snyder, 1999, p. 258).

Todas ellas reflejan diferentes perspectivas del concepto. Sin embargo, la definición con la que este artículo guarda una mayor afinidad, por ser comprehensiva de las anteriores, es la de Rosal (2003). En este estudio se hablará de actitud esperanzada en el sentido que expresa el autor:

Una actitud esperanzada, como concepto psicológico social, que se manifiesta por:

A) un componente afectivo profundo de carácter gratificante y energetizador hacia la acción, un tipo de estado de ánimo alegre.

B) un componente cognitivo relacionado, que consiste en que "ciertas metas relevantes para que la propia vida tenga sentido...tienen un alto grado de probabilidad de ser alcanzadas, si uno coopera en ello.

C) un componente conductual de esta actitud como conducta activa, energetizada a partir de los dos componentes anteriores.

D) Este conjunto de pensamientos y sentimientos se apoyan en convicciones científicas, filosóficas o de fe.

E) Dichas convicciones no son "meras fantasías derivadas de deseos inconscientes. (Rosal, 2003, pp28s.).

\section{¿Cómo justificar la actitud esperanzada como actitud ética?}

Se enmarca este estudio en una ética naturalista no reduccionista desde una perspectiva integracionista (Rosal, 2003). Desde esta concepción ética, se entienden las actitudes humanizadoras como valores/virtudes, y por tanto, "éticamente positivas, no a partir de determinados estilos socio-culturales, sino a partir del conocimiento psicológico de tendencias del ser humano en proceso de autorrealización" (Rosal, 2003, p. 238). Es una ética pues antropológico-psicológica. Desde aquí, el cultivo y desarrollo de diferentes actitudes éticas contribuyen al crecimiento personal, buscando "una ética inmanente al ser humano maduro" (Ibidem), entre ellas la actitud esperanzada. 


\section{EI modelo de la Psicoterapia Integradora Humanista}

Se trata de un Modelo de psicoterapia creado en el Instituto Erich Fromm de Barcelona por Rosal y Gimeno-Bayón en los años 80 . Sus principios metateóricos principales son: epistemológicamente constructivista, entiende la realidad de forma sistémica, existencialista, considera a la persona como parcialmente libre y le da relevancia a su proyecto vital y al sentido que otorga a su vida. Asimismo, se interesa de forma primordial por los temas específicamente humanos. ¿Y qué es sino la esperanza? Dice Laín-Entralgo:

La esperanza, más que una pasión es un constitutivum de la existencia humana, un modo de ser tan inherente al sentimiento de la vida, es decir, a la vida misma, como el pensamiento, el amor de sí mismo y el deseo del propio bien. Como el hombre no puede no pensar, de igual modo no puede no esperar (Laín-Entralgo, 1957, p.238).

Entre sus principios teóricos, sostiene la naturaleza psicodinámica de la psique, acepta la variabilidad en las motivaciones humanas, distinguiendo ente motivaciones y metamotivaciones y sitúa a los valores éticos como una parte importante en el núcleo de la personalidad. Dicha personalidad constituye "una estructura dinámica y relativamente estable...integradora de rasgos somáticos, cognitivos, emocionales, práxicos y existenciales, mediante la cual el individuo influye en su ambiente y se deja influir por él" (Gimeno-Bayón, 1996 pp.14s.). La personalidad resulta pues en una manera única de desplegarse para satisfacer necesidades.

Tomando como base el ciclo de satisfacción de necesidades de la Psicoterapia de la Gestalt y enriqueciéndolo, entre otras, en sus fases Valorativa y Decisional, plantean el siguiente modelo de fases del fluir vital :

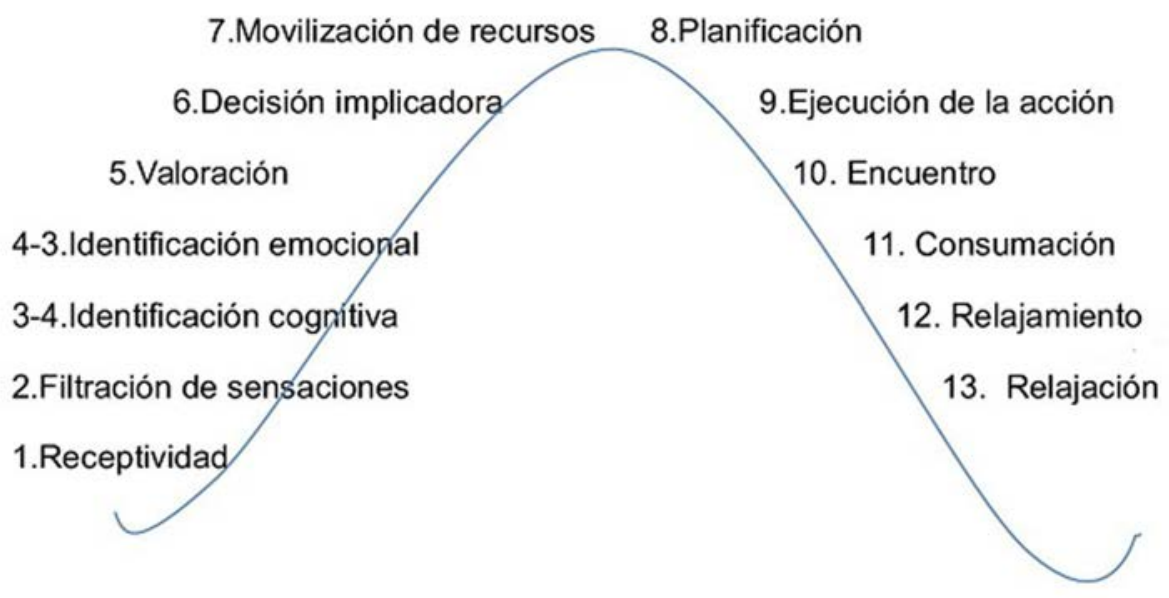

Figura 1.

Vacio Fértil

Ciclo del fluir vital en la Psicoterapia Integradora Humanista (Gimeno-Bayón \& Rosal, 2016). 
Desde este modelo, se entiende que, cualquier proceso humano, para poder ser considerado sano, debe ser fluido, entendiendo por fluidez el paso por estas fases del ciclo libre de bloqueos, dispersiones o distorsiones. Así, los diferentes problemas o trastornos psicopatológicos, serán considerados y diagnosticados como diferentes tipos de bloqueos, dispersiones o distorsiones en cualquiera de las fases que constituyen el ciclo del fluir vital. Se entiende también que dichos problemas afectarán a las fases sucesivas a aquellas donde estos se produzcan.

En lo que concierne a las actitudes éticas, a su vivencia y cultivo, como procesos naturalmente presentes en el ser humano y constituyentes del mismo, podrán desarrollarse y vivenciarse, siguiendo el ciclo anterior, de una manera fluida o armoniosa, o bien podrán darse bloqueos, dispersiones o distorsiones en este fluir que se conviertan en obstáculos para el bienestar psicológico y aún para la realización de un proyecto existencial libre y nutricio.

Por otra parte, siguiendo a Rosal, (2014):

...previamente a la capacidad psicológica valorativa -para la captación de valores éticos- se encuentran implicados procesos sensoriales, emocionales y cognitivos... un funcionamiento sano de estos es un requisito para una vivencia satisfactoria de la captación de valores (Rosal, 2014, p. 4).

Como puede observarse en la figura 1, dichas capacidades sensoriales y cognitivo-emocionales corresponden a las 4 primeras fases del ciclo de satisfacción de necesidades.

El modelo de la Psicoterapia Integradora Humanista, ha hallado y diagnosticado más de 103 problemas que pueden darse en las diferentes fases del ciclo (Gimeno-Bayón \& Rosal, 2016), y nos ofrece, como veremos más adelante, diferentes intervenciones para cada uno de ellos.

\section{Descripción de un caso clínico: pasando de lo general a lo particular}

\section{Presentación del caso}

Hombre, 58 años. Soltero. Se dedica al comercio textil. Presencia física grande, voz profunda y grave. Discurso abierto y fluido. Colaborador y extravertido. Actitud depresiva. Cierta ansiedad. Se advierte cierta incomodidad por el estado en el que se encuentra, como si estuviera en un sitio que no le toca.

Historia familiar. El cliente refiere un ambiente familiar con muchas comodidades materiales, pero con muchas dificultades emocionales. Convivían, en una masía familiar, sus padres, su abuela materna y él mismo, que es hijo único. Su padre presentaba una "personalidad segura" (Millon \& Everly, 1994), empresario de éxito y muy dominante. Como el cliente dice, con ironía, era una personalidad "yo-yo". La madre, presentaba una personalidad de tipo dependiente, sumisa a los dictados del padre, y tanto ella como su abuela le sobreprotegían. Recuerda una infancia libre, jugando en el jardín, sin ninguna responsabilidad y, aunque refiere episodios de conflictividad familiar, sobre todo entre su abuela y su padre, él permanecía 
alejado de ellos. En la adolescencia y posterior adultez joven, la relación con el padre se fue deteriorando. Éste esperaba que su hijo, "el heredero", se hiciera cargo del negocio familiar, y que lo hiciera a su manera, ;claro! Tras unos años de convivencia laboral y personal tormentosa, aunque muy cómoda a nivel material, a los 30 años, decide independizarse y tomar su camino. Dicha decisión ahonda la brecha emocional y relacional con su padre: "estos años teníamos como una especie de pacto de no agresión, algo así como cada uno hace su vida y no nos molestamos". Posteriormente, la muerte de la madre afianzó dicho pacto tácito. La vida del cliente discurría, una vez cursados estudios empresariales y en un buen puesto de trabajo, de forma muy plácida. Desde siempre, las actividades hedonistas le habían resultado muy atractivas y placenteras. Puede decirse que, gran parte de su tiempo libre, lo ha dedicado y dedica a jugar, a lo lúdico. "Toda la vida he pensado que hemos venido a este mundo a pasarlo bien..." Cuenta con muchos amigos y amigas con los que juega a golf, explora la gastronomía... A nivel afectivo, recuerda dos relaciones afectivas importantes, y en las dos, en el momento de comprometerse, se deprimió, inexplicablemente para él, "sobre todo con la primera, era una chica excelente...pero no pude...la dejé". Una tercera relación, tras estas dos, la ha ido manteniendo durante los últimos 15 años, a un nivel de no compromiso.

Llegados a este punto, se dan dos situaciones, que además confluyen temporalmente, y que parecen amenazar su bienestar psicológico: por un lado, su padre, que cuenta ahora 85 años, atraviesa dificultades económicas, así como las propias de una salud que se deteriora y "rompe" el pacto tácito de estos años, solicitándole ayuda económica. Por otro, la relación afectiva que mantenía amenaza romperse, cuando la mujer decide irse al extranjero por periodo de un año, en parte cansada por la situación de impasse en que se encuentran.

El cliente se desborda emocionalmente y desarrolla sintomatología depresiva, con tristeza, ansiedad psíquico-somática, apatía, anergia, cogniciones negativas y trastornos del sueño.

Presenta mucha rabia hacia su padre, con estallidos frecuentes, seguidos de cierta culpa. Una inestabilidad emocional que no consigue resolver. Por otra parte, la ausencia de su pareja da como resultado un sentimiento de pena profundo, que lo sume en, como dice él, "una crisis vital". Tras medicarse con antidepresivos y ansiolíticos, decide acudir a consulta psicológica.

Motivo de consulta. Motivo principal: Trastorno adaptativo con síntomas depresivos. Dificultad de gestión emocional y posicionamiento respecto a una situación sobrevenida: hacerse cargo -tanto en lo económico como en lo relacionalde su padre (de 84 años) con el que mantiene una relación distante, desde hace años.

Impasse con una relación de muchos años con la que no acaba de comprometerse (problema secundario que se fue desvelando a lo largo del proceso terapéutico).

Métodos diagnósticos. El diagnóstico inicial (provisional, siempre sometido a revisión conforme transcurre el proceso), se basó en una entrevista semi- 
estructurada de dos horas, en la cual se realizaron dos fantasías guiadas (a modo de test proyectivo) y se aplicaron dos cuestionarios. Las fantasías guiadas fueron las siguientes:

a) Encuentro y conversación con la persona sabia, (Stevens, 1976, pp.163s.). Se trata de un ejercicio de visualización mental proveniente de la Psicoterapia de la Gestalt. Su uso en este momento de la terapia permite sensibilizar al cliente para trabajos proyectivos, así como recabar información no consciente sobre sí mismo, su autopercepción y sus necesidades.

b) Escribir un cuento de animales (O'Hearne, 1977). Es un test proyectivo proveniente del Análisis Transaccional. Permite conocer el esquema relacional y de solución de problemas del cliente, así como algunos aspectos importantes de su proyecto vital no consciente, decidido prematuramente (el constructo "guión de la vida").

Durante la entrevista, se aplicaron dos cuestionarios objetivos: Adult Hope Scale (HS) (Snyder, et al. 1991) y la Beck Hopelessness Scale (BHS), (Beck, Weissman, Lester \& Trexler, 1974). El resultado de estos cuestionarios fue el siguiente:

a) Escala de Esperanza de Snyder et al. (1991), (HS) : 11. Muy baja esperanza

b) Escala de desesperanza de Beck et al. (1974), (BHS): 18. Alta desesperanza.

Diagnóstico triple complementario. Es común, en la práctica clínica en el Instituto Erich Fromm, en el que se desarrolla una parte de la actividad como terapeuta del autor, presentar un diagnóstico triple, complementario: con DSM-IVR ó DSM-V, un segundo desde el Análisis Transaccional y un tercero desde la Psicoterapia Integradora Humanista. Dado el objetivo de este artículo, me limitaré a describir el diagnóstico con el DSM-IV-R y desde la Psicoterapia Integradora Humanista, en las cinco primeras fases del ciclo, las pertinentes para el estudio que aquí se presenta. Asimismo, se muestran los resultados cuantitativos de los cuestionarios objetivos administrados, pre y post-tratamiento, simplemente a nivel informativo. El análisis cuantitativo de los mismos desborda el objetivo de este artículo. Puede verse dicho análisis como parte del estudio presentado en las III Jornadas de la APIH (Asociación de Psicoterapia Integradora Humanista, 2014), titulado "La psicoterapia como constructora de esperanza: un estudio empírico". (Oriol, 2014).

Según el DSMI-IV-R.

Eje I: F.43.22 Trastorno adaptativo mixto con ansiedad y estado de ánimo depresivo [309.28].

Eje II: Rasgos importantes de personalidad sociable (Millon \& Everly, 1994) Eje III: Ninguno.

Eje IV: Problemas relativos al grupo primario de apoyo. Conflicto relacional. Eje V: EEAG 55. 
Análisis diagnóstico con Psicoterapia Integradora Humanista (PIH).

Desde este modelo, la vivencia sana de cualquier virtud y/o potencial humano se corresponde con un buen fluir vital entre las diferentes fases que constituyen el ciclo de la experiencia humana.

El diagnóstico desde este modelo consiste, a nivel "macro" en el análisis del proyecto existencial y de los valores que lo sustentan. A nivel "micro", consiste en la evaluación e identificación de diferentes problemas observados en el fluir vital del cliente, tomado como un proceso de resolución de problemas o satisfacción de necesidades en relación con el conjunto del proyecto vital. Proceso en el que pueden darse bloqueos, dispersiones o distorsiones en cada una de las fases del ciclo. Gimeno-Bayón y Rosal (2016) describen cada uno de los problemas, observaciones para su identificación y procedimientos de intervención de probada eficacia clínica, de los diferentes modelos integrados en diferentes niveles de profundidad en el modelo de la Psicoterapia Integradora Humanista.

De forma holística, se puede observar un bloqueo en la vivencia de la actitud esperanzada ligada al síndrome depresivo del cliente. Y una distorsión de dicha actitud, a nivel más profundo, ligada al estilo de personalidad del cliente, hedonista, presentista, traducido en una vivencia de la actitud esperanzada de esta misma forma, "resbalando" por la superficie de la misma, (Rosal, 2003). Dice el cliente: “...yo, he ido haciendo...decidí, tengo que pasármelo bien, tú...".

Ahora, las circunstancias y el momento vital lo ponen delante de tener que "hacerse cargo", "responsabilizarse" de su posición en el mundo. No hay esperanza sólida porque no hay metas profundas, y las metas hedonistas se agotan en sí mismas. También porque existe miedo/desconfianza a no poder hacer frente a las que la vida le propone.

Así, dichos problemas holísticos en la vivencia sana de la actitud esperanzada, pueden operativizarse en diferentes bloqueos, distorsiones y dispersiones en cada una de las fases del Ciclo del Fluir Vital. Se procede a continuación a indicar la presencia de los diferentes problemas observados en las cinco primeras fases del Ciclo, junto con una breve descripción del mismo, acompañado de datos del cliente que permitan identificar dicho problema.

\section{Fase 1. Receptividad sensorial}

- Dispersión. Problema: Dispersión externa: exceso de estímulos ambientales. Descripción: como su nombre indica es un problema ambiental, salvo como ocurre en este caso, que el cliente busque o cree este ambiente abigarrado de estímulos.

Identificación: El cliente mantiene un nivel de estimulación constante y positiva que permite pocos momentos de vacío"...me cuesta mucho estar en silencio...siempre me lleno de actividades los fines de semana...".

- Distorsión. Problema : Prejuicio sensorial

Descripción: la sensación aparece contaminada por un juicio previo que 
puede distorsionar la información que llega a nuestros sentidos.

Identificación: Observamos este problema respecto a las sensaciones/emociones negativas. Presenta una vivencia perturbadora de dichas sensaciones/ emociones, y desea eliminarlas sin pararse a entender su significado. Referido a una situación de conflicto paterno: “...no necesito pasar por aquí..., no quiero..., a mí no..., no he venido aquí a sufrir...”.

\section{Fase 2. Filtración de sensaciones.}

En esta fase "se decide" (habitualmente en forma inconsciente) a qué clase de sensaciones dejaremos pasar en nuestro filtro perceptivo y, por tanto, a partir de cuáles de éstas seguiremos el ciclo.

- Bloqueo. Problema: Falta de atención a elementos que aportan información relevante.

Descripción: la persona bloquea el acceso a determinados tipo de sensaciones, que son negadas. Esto genera una falta de visión panorámica de la situación.

Identificación: se puede enlazar con los problemas de la fase anterior. Además se observa claramente en la percepción que el cliente tiene de su padre, que cuenta con 84 años. Parece que aquellos datos que dan fe de la vejez de su padre son despreciados, negados. Presenta mucha rabia contra él, como si estuviera delante de aquel padre joven.

\section{Fase 3-4 Identificación Cognitiva.}

- Distorsión

a) Problema: Confusión dentro-fuera

Descripción: Se refiere a la perturbación en los límites de contacto entre lo de dentro del sujeto y lo externo a él (Gimeno-Bayón \& Rosal, 2016; Perls,1973). Puede referirse a la introyección, la proyección o la confluencia.

Identificación: Se puede observar un estilo proyector en el cliente” ¡Pero qué quiere ahora de mí! (refiriéndose a su padre)...es su problema no haber sabido planear su vejez...". Se desvincula de examinar su responsabilidad respecto a la situación que vive su padre anciano a través de proyectar culpa. Ocurre también así respecto a su pareja "...nunca la he engañado..., siempre ha sabido cómo soy..., ahora no sé qué quiere de mí...”.

b) Problema: Proyección de una situación del pasado

Descripción: Si antes describíamos una confusión dentro-fuera, este problema se refiere a una confusión ayer-hoy. Cuando esto ocurre "hay una serie de estímulos similares a las de algunas situaciones que existieron en el pasado... que llevan a una idéntica interpretación" (Gimeno-Bayón \& Rosal, 2016).

Identificación: siguiendo con el conflicto con su padre, dice el cliente: “...ya está como siempre, yo-yo... y a los demás ¿qué?...siempre tan egoísta...”. Minusvalora el hecho de que, hoy, el "egoísmo" de su padre no es sino necesidad pura por una disminución acusada de sus capacidades motrices, visuales...y 
económicas.

c) Problema: Proyección de deseos o temores

Descripción: Problema que refiere a un contacto con la realidad en forma distorsionada, en base a una deformación optimista de la misma, en el caso de la proyección de deseos, o una distorsión negativa o pesimista, en el caso de la proyección de temores. Este último supuesto es el que presenta el cliente.

Identificación: se observa desde la fase depresiva en que se encuentra: “...no sé qué hacer, no veo salida..., nunca me había sentido así..., no voy a poder con esto...".

\section{Fase 4-3 Identificación afectiva.}

- Bloqueo. Problema: Emociones prohibidas

Descripción: Se trata de la represión de la experiencia emocional en algún grado, bien de forma general (desconexión) en los casos más graves; o bien, en casos más leves, en la represión de alguna emoción concreta, o en la expresión o actuación de la misma.

Identificación: Se observa respecto a las emociones "negativas", concretamente respecto a la tristeza. A pesar de que ahora se muestre de forma patológica, la emoción de tristeza se encuentra ausente en la experiencia emocional habitual del cliente, fruto de su posición vital “... hemos venido a pasarlo bien... nunca me siento así... mis amigos están alucinando”.

- Dispersión. Problema: Conflicto entre distintas emociones

Descripción: Presencia simultánea de dos emociones de valencia contraria que generan movimientos internos emocionales con diferente orientación, produciendo en muchas ocasiones una parálisis en el fluir vital.

Identificación: “...no sé qué hacer... siento mucha rabia hacia él (padre)..., pero después de discutir no me quedo bien..., estoy hecho un lío...". Como en fases posteriores pudo comprobarse, el cliente vivía un conflicto entre la rabia y la compasión, emoción ésta todavía no identificada de forma plena al inicio del proceso terapéutico.

- Distorsión.

a) Problema: Falsa identificación por proyección en el presente de una situación pasada.

Descripción: Sería la contrapartida emocional al problema de Proyección de una situación del pasado de la fase anterior, la de Identificación Cognitiva.

Identificación: El cliente vive las demandas del padre como un "abuso de su relación", respondiendo con una rabia intensa y, desde el punto de vista del terapeuta, desproporcionada.

b) Problema: Descontrol emocional (tristeza/ansiedad)

Descripción: Se caracteriza por la incapacidad de la persona de acceder a sus recursos para regular sus emociones.

Identificación: Se observa la tristeza patológica como parte de su síndrome 
depresivo, así como de episodios puntuales de ansiedad nocturna y de accesos de rabia referidos por el cliente.

c) Problema: Aprendizaje distorsionado de la vivencia emocional

Descripción: Se refiere al tipo de aprendizaje emocional que propició el ambiente familiar: desde fomentar la represión del mundo emocional parcial o totalmente, hasta el abandono o las deficiencias de educar en la vivencia y regulación del mismo.

Identificación: Observamos sobreprotección materna, con falta de límites, y represión paterna.

\section{Fase 5. Valoración.}

- Bloqueo. Problema:_Fobia al compromiso con valores.

Descripción: La persona detiene el compromiso con valores en su fase inicial, a partir de una proyección negativa de las consecuencias de dicho compromiso.

Identificación: respecto a las relaciones afectivas "huy, huy, huy..., el compromiso me da miedo..., no sé..., es extraño..., no te lo sé explicar, pero necesito espacio...".

- Dispersión. Problema: Dificultad en la jerarquización de valores.

Descripción: en este problema la persona duda qué valores, dada una situación, son más importantes o básicos.

Identificación: siguiendo con la situación anterior, pasadas unas sesiones " no sé..., estoy bien con ella, la quiero..., ¿debería proponerle algo? (valor compartir)..., no sé..., ir a vivir juntos..., pero quiero seguir con mis partidas de golf de los domingos (valor libertad)..., no sé...”.

- Distorsión. Problema: Conciencia inmadura

Descripción: este problema hace referencia al desfase que se produce entre el momento vital de la persona y su madurez ético-valorativa.

Identificación: el cliente se encuentra, siguiendo la clasificación de desarrollo moral de Kolhberg (1969), en el Nivel I o Preconvencional, Estadio 2: Moral individualista: “ hemos venido a pasarlo bien tú...”. O cuando se enfrenta a situaciones que generan emociones negativas "no quiero pasar por esto..., no debería pasar por esto..., yo nunca he engañado acerca de quién soy..., no es mi problema".

\section{Dinámica general del proceso}

La terapia se inició en Octubre de 2014 y está activa en este momento (45 sesiones), ahora con periodicidad quincenal, dado que el trabajo está focalizado en el crecimiento personal del cliente, una vez solucionada la demanda sintomatológica.

En las primeras sesiones se trabajó con escucha activa todo lo que rodeaba a su situación vital actual, $\mathrm{y}$, a través de diferentes ejercicios experienciales con fantasía (referidos al inicio) invitamos al cliente a tomar contacto con esta forma de trabajo, ajena a él, dado el poder de las imágenes para soslayar las posibles 
resistencias (Rosal, 2013) e ir desvelando diferentes aspectos de la personalidad del cliente. Esto mismo iba funcionando como una especie de desensibilización sistemática hacia sus emociones/sensaciones desagradables, que redundó en una forma de comunicación con él mismo progresivamente más profunda y significativa.

Tras estas primeras sesiones de diagnóstico y creación de un vínculo terapéutico seguro y respetuoso con el ritmo del cliente, el trabajo se focalizó en lo que se fue desvelando como el conflicto más doloroso para él en ese momento: la relación tormentosa con su padre. A través de diferentes procedimientos que se concretarán en el siguiente apartado (Tablas 2 y 3 ), se trabajó en la identificación emocional de los diferentes movimientos emocionales que se suscitaban en el cliente en esta relación, tratándolos como información, aunque en ocasiones contradictoria (rabia versus compasión), que daban fe de diferentes tendencias del cliente, las dos. Este descubrimiento dio una nueva perspectiva del problema al cliente, pues cualquier solución al dilema emocional no podía pasar por "eliminar" una parte del mismo, como él había ensayado en ocasiones con escaso éxito "...que se apañe él solo..." sino por la integración de ambas tendencias. Fue un trabajo complejo y con diferentes altibajos emocionales.

Progresivamente, el cliente pudo elaborar una nueva actitud, más integrada y egosintónica, hacia su padre “...no podré quererlo a rabiar..., pero lo voy a cuidar, voy a hacerme cargo de él respetando lo que siento...”.

El trabajo en una progresiva identificación y profundización de su experiencia emocional le fue desvelando diferentes interrogantes sobre quién era él, sus valores, el sentido de su vida “...tengo la sensación que he perdido tanto el tiempo... evitando aquello que me molestaba...". No es extraño, ya que como apunta Gimeno-Bayón: El tratamiento de los valores afecta al subsistema emocional (nos emocionamos respecto a lo que consideramos valioso, a lo que nos importa, y por tanto es un valor para nosotros)...lo que hará que el detenimiento del desarrollo ético comporte detenimiento psicológico y a la inversa (GimenoBayón, 2014, p. 67).

En este momento del proceso (sesión 20), la mejoría sintomatológica es evidente y permite centrarse en estos aspectos más profundos. Se utilizaron para ello trabajos con imágenes y fantasía, propios de la Psicoterapia Integradora Humanista, que se relacionarán en el apartado siguiente (Tabla 4). Fruto de este trabajo, el cliente contacta con aquello que le ha faltado en su proyecto vital y que quiere que forme parte del mismo en el futuro para llegar a ser un proyecto vital pleno para él. Como parte de este proyecto maduro lleno de sentido aparece su deseo de una relación afectiva profunda. Esto le lleva a dar un paso de compromiso con la relación con una mujer con la que lleva "saliendo" durante años como pasatiempo.

Se llega así al momento actual del proceso, en el que el foco está en cristalizar lo madurado y pasar, siguiendo a Kohlberg (1969), de una ética pre-convencional hedonista (estadio 2) a una ética madura que responda a la persona que desea ser, 
más allá de limitaciones o decisiones antiguas de su etapa infantil que aún hoy arrastra, faltas de libertad.

\section{Procedimientos de intervención}

En este apartado se relacionarán, en las tablas que se muestran a continuación, los diferentes procedimientos de intervención para los distintos bloqueos,

distorsiones y dispersiones diagnosticadas en las tres fases del ciclo vital que presentaban un mayor número de problemas y en los que se centró el proceso psicoterapéutico . En negrita, se señalan aquellos problemas de cada fase que demostraron una mayor relevancia en la génesis y/o mantenimiento del malestar del cliente y, por tanto, con mayor relevancia también en la resolución del proceso.

Como podrá comprobarse, la mayoría de ellos son procedimientos con implicaciones de la imaginación y psicocorporales, procedimientos que han mostrado en la práctica clínica su eficacia para los problemas diagnosticados. Una vez relacionados, se procederá a mostrar la aplicación en sesión de aquellos que, según el informe de evaluación del proceso terapéutico del cliente, le resultaron de más ayuda. Se hacía siguiendo la metodología de acontecimientos de cambio intrasesión de Greenberg, Rice y Elliot (1996).

Tabla 1

Fase 3-4 Identificación Cognitiva

Problemas diagnosticados Intervención

DISTORSIÓN

\begin{tabular}{ll}
\hline Introyección-Prejuicio & Eidetic Parent (Ashen, 1972 ). \\
\hline Proyección de una situación del pasado & $\begin{array}{l}\text { Trabajo en fantasía con visualización de } \\
\text { dos pantallas: diferenciación pasado/ } \\
\text { presente (Gimeno-Bayón \& Rosal, 2016). }\end{array}$ \\
\hline Proyección de deseos o temores & $\begin{array}{l}\text { Trabajo en fantasía: enfrentamiento a los } \\
\text { miedos y conexión con los recursos } \\
\text { (Gimeno-Bayón \& Rosal, 2017). }\end{array}$ \\
\hline
\end{tabular}


Tabla 2

Fase 3-4 Identificación Afectiva

Problemas diagnosticados

Intervención

BLOQUEOS

Emociones prohibidas

Trabajo con fantasía e implicación corporal para la identificación y clarificación de las 4 emociones básicas (Moiso, 1983;

Gimeno-Bayón, 1996).

DISPERSIÓN

Conflicto entre distintas emociones

Diálogo gestáltico entre la Rabia y la

Compasión (Levitsky \& Perls, 1973).

DISTORSIÓN

Falsa identificación por proyección en

Diálogo gestáltico con el padre de 40 años.

el presente de una situación pasada

Trabajos con fantasía con el padre actual

(Levitsky \& Perls, 1973, Greenberg, Rice \& Elliot, 1996).

Descontrol emocional

Eye Movement Therapy (TMO Frieldberg, 2003)

Aprendizaje distorsionado de la vivencia emocional

Trabajo con la dinámica del proceso emocional (Moiso, 1983; Gimeno-Bayón, 1996).

Desplazamiento de la afectividad a

Esculpiendo mis emociones (Gimenootros niveles de la Personalidad Bayón, 1985).

Tabla 3

Fase 5 Valoración

Problemas diagnosticados

Intervención

BLOQUEOS

Fobia al compromiso con valores

Fantasía de la Obra de Teatro. Encuentro y diálogo con el Yo anciano (Berne, 1973; Gimeno-Bayón, 2012).

DISPERSIÓN

Dificultad en la jerarquización de valores Fantasía de la Obra de Teatro. Trabajo con el epitafio (Berne, 1974).

DISTORSIÓN

Conciencia inmadura (Kolhberg)

Trabajo con fantasía sobre los criterios sobre lo Bueno y lo Malo (Gimeno-Bayón \& Rosal, 2017) 


\section{Descripción de dos sesiones}

La descripición de las mismas se realiza utilizando la metodología descriptiva de Greenberg, et al. (1996) para los acontecimientos de cambio intrasesión.

\section{1.-Sesión novena: Diálogo gestáltico entre la Rabia y la Compasión.}

\section{Señal del cliente:}

F. sufre una gran ambivalencia emocional respecto a su padre, y dicha ambivalencia lo bloquea y le genera mucho sufrimiento. Pasa de episodios de rabia explosiva, cuando percibe que su padre quiere "volver a dominar la situación como entonces..." a una pena y culpa más tarde, cuando recuerda la situación y se da cuenta de que su padre está muy mayor. No consigue salir de este bucle.

\section{Actuación del terapeuta:}

El terapeuta le plantea un diálogo gestáltico en la silla vacia entre ambas emociones en conflicto. Con esto pretende, a través de un proceso de diferenciación física entre ambas emociones, "sentando" a cada una de ellas en un sitio diferente, fomentar el conocimiento entre ambas y favorecer su mutuo reconocimiento y posterior integración. Se indica al cliente que ocupe, alternativamente, ambos lugares, que se identifique con la emoción en la que se encuentra y que, desde ahí le explique a la otra emoción quién es, qué hace aquí, qué intención le mueve, cómo se siente respecto a ella... Se le invita a hacer lo propio desde la otra emoción y se favorece el diálogo entre ambas, trabajando el reconocimiento de que ambas forman parte del cliente y explorando aquello que aportan de positivo en su vivencia.

\section{Actuación del cliente (resumida):}

- Desde la Rabia:

Estoy aquí para que te des cuenta de que te sientes traicionado por tu padre..., teníais un acuerdo de no agresión... y ahora no tienes más remedio que hacerte cargo...es injusto que esto caiga sobre mí..., no hay derecho..., estoy aquí para protegerte y que no te tome el pelo..., además económicamente te quedas tocado, ¿y tus aficiones?..., no es justo.

- Desde la Compasión:

Date cuenta... cada vez tu padre es más dependiente... está muy mayor... estoy aquí para señalarte que debes tener esto en cuenta... realmente necesita tu ayuda... y para decirte que no es un opción para ti abandonarlo -el cliente se emociona- sería muy cruel y tú no lo eres... es así. Eres generoso en tu vida en general, así que....

-Diálogo : La Compasión a la Rabia:

tienes razón en muchas cosas de las que dices..., ¿pero de qué sirve?.., no me es útil..., si tú dominas yo no estoy bien...te necesito para que me muestres cuáles son mis límites con él, para no hacer lo que no quiera hacer...,pero que me dejes 
hacer lo que espontáneamente me surja...

- Responde la Rabia:

Es razonable, me cuesta desde aquí, pero me doy cuenta de que no te voy bien, que no vamos a estar bien... ¿sabes?, no lo voy a querer como si hubiera sido un padre amoroso y estaré aquí para recordártelo..., pero supongo que puedo aflojar y ver si nos podemos entender mejor tú y yo....

\section{Cambio intra-sesión.}

El cliente se siente más tranquilo e integrado tras el diálogo. Ha podido conectar con una parte generosa a la que no puede renunciar en el trato con su padre. Asimismo, puede reconocer una función positiva en la rabia y, desde este conocimiento, poder diferenciarla de la rabia excesiva, para modular ésta última. Pero sobre todo, ha podido experienciar que ambas emociones pertenecen a su mundo emocional particular, y que no puede eliminar a ninguna de las dos sin que su vivencia quede disminuida en algún sentido.

\section{Cambio inter-sesiones.}

En las sesiones posteriores se realizó algún diálogo más para acabar de integrar ambas emociones en conflicto. La relación con el padre va mejorando progresivamente, y el cliente manifiesta que ahora "incluso puedo disfrutar de algunos momentos con él..., otros aún me cuestan". Se encuentra en un camino ya sólido de aceptación tanto de él mismo como de su padre.

\section{2.- Sesión vigésima. Fantasía de la Obra de Teatro.}

\section{Señal del cliente.}

A través del trabajo en las sesiones, el cliente se siente inquieto ante la percepción de que necesita una orientación vital en el futuro, un "sentido" diferente en todo caso al que parece que le ha animado hasta hoy. Llega a verbalizar: "¿Quién soy yo?".

\section{Actuación del terapeuta.}

Le propone un trabajo con fantasía guiada, concretamente la Fantasía de la Obra de Teatro (Berne, 1974). Se pretende una visión panorámica de diferentes aspectos del proyecto vital, muchas veces inconsciente. Se invita al cliente de forma respetuosa a ver una obra de teatro que alguien ha escrito sobre su vida, desde la escena de su infancia hasta la de su muerte. Tras esta, se acompaña al cliente a visualizar su epitafio. Tras la fantasía, se elabora con el cliente el material vivenciado. 


\section{Actuación del cliente.}

Vivencia profundamente la fantasía. Dice al acabar:

me he metido mucho..., tras la primera escena de mi infancia que era de alegría y libertad total, jugando por la masía a mi antojo..., la última escena has sido muy dura, me veía sólo en un hospital... me he dado cuenta que lo valioso para mí ha sido la amistad y el disfrute..., pero he sentido claramente que echaba en falta querer, querer a alguien profundamente, quizás una pareja..., también me pesaba haber renunciado a ser padre.

Cuando el terapeuta pregunta por el epitafio dice que era algo así como "No ha vivido en paz". Le propone que tome conciencia de qué significa para él y responde "no vivió intensamente..., falta de profundidad..., no tomó riesgos. Tomo conciencia de que es un camino que quiero recorrer, aunque me sea extraño...".

\section{Cambio intra-sesión.}

El cliente se siente conmovido por su insight y también más orientado. Da muestras tanto verbales como no verbales de la profundidad y veracidad de sus "hallazgos" interiores. "Sí, sin duda es esto, necesito pararme, estar conmigo, hacer estos ejercicios yo mismo, fuera de aquí...".

\section{Cambio inter-sesiones.}

Terapeuta y cliente siguen trabajando en sesiones posteriores con el epitafio deseado por el cliente y cómo dirigirse hacia allí. Se suscita en el cliente un deseo claro de convivir, comprometerse con la pareja con la que ha estado muchos años en una relación sin proyecto. Emocionalmente, se siente más alegre y orientado.

\section{Resultados post-intervención}

\section{DSMI-IV-R.}

Eje I: Z03.2 Sin diagnóstico [V71.09]

Eje II: Z03.2 Sin diagnóstico [V71.09] Rasgos de personalidad sociable (Millon \& Everly, 1994).

Eje III: Ninguno.

Eje IV: Problemas relativos al grupo primario de apoyo. En fase de resolución. Eje V: EEAG: 80.

\section{Resultados cuestionarios.}

Escala de Desesperanza de Beck et al. (1974) (BHS): 1. Baja desesperanza. Escala de Esperanza de Snyder et al. (1991) (HS): 43. Alta esperanza.

Cambios operados con diagnóstico Psicoterapia Integradora Humanista. Los cambios, desde el punto de vista del diagnóstico desde este modelo son los que se reflejan en la Tabla 4. 


\section{Tabla 4}

Fase 3-4 Identificación cognitiva

Problemas diagnosticados Resultado

DISTORSIÓN

Introyección-Prejuicio

Mejorado.

Proyección de una situación del pasado Resuelto. Actualmente el cliente se relaciona de forma "actualizada" con su padre anciano.

Proyección de deseos o temores En vías de resolución. El cliente ha enriquecido su proyecto vital y lo está recorriendo. Aún surgen algunos temores, que va trabajando.

\section{Tabla 5}

Fase 4-3. Identificación afectiva

Problemas diagnosticados

Resultado

\section{BLOQUEOS}

\section{Emociones prohibidas}

Mejorado. Progresivamente, el cliente puede acceder a su mundo emocional de forma más sana.

DISPERSIÓN

\begin{tabular}{ll}
\hline Conflicto entre distintas emociones $\quad$ Muy mejorado. \\
\hline DISTORSIÓN
\end{tabular}

Falsa identificación por proyección en Resuelto. el presente de una situación pasada

Descontrol emocional Resuelto. Sin episodios depresivos y/o ansiosos.

Aprendizaje distorsionado de la vivencia Mejorado/en resolución. Sigue trabajando emocional Desplazamiento de la afectividad a otros en una vivencia emocional más sana y niveles de la Personalidad diferenciada. 
Tabla 6

Fase 5. Valoración

Problemas diagnosticados

Resultado

BLOQUEOS

Fobia al compromiso con valores Muy mejorado. El cliente se muestra decidido a ser fiel al Proyecto vital elegido.

DISPERSIÓN

Dificultad en la jerarquización de valores Muy mejorado. Aparecen claras sus

prioridades vitales en este momento.

DISTORSIÓN

Conciencia inmadura

Mejorado/en proceso de resolución. El

cliente se encuentra en un proceso

madurativo sano.

\section{Conclusiones}

Se puede afirmar, tras examinar los resultados post-intervención, que se ha solucionado el bloqueo en la vivencia de la actitud esperanzada, parejo a la resolución del síndrome ansioso-depresivo, síndrome que resultaba de la incapacidad del cliente para manejar, de forma sana, las emociones suscitadas por una relación afectiva complicada con su figura paterna. Por otra parte, se señalaba una dispersión de dicha actitud, más profunda, ligada a un proyecto vital hedonista y presentista, con una vivencia de la actitud esperanzada superficial y corta de miras. En estos momentos del proceso terapéutico, el cliente muestra una mayor conciencia y profundidad en la vivencia de sus valores personales, ahora libremente elegidos. Esto se traduce, entre otras vivencias, en una actitud esperanzada renovada, que se estira hacia el futuro, acompañada de un estado emocional alegre y sereno.

Se ha mostrado, asimismo, la bondad de las intervenciones desde la Psicoterapia Integradora Humanista, poniendo el énfasis en aquellas de índole imaginativa y psicocorporal, para la resolución de los diferentes bloqueos, dispersiones y distorsiones de la actitud esperanzada, resultando en un incremento de "eticidad" en la vivencia de dicha actitud y por ende, en el crecimiento personal del cliente.

\section{Referencias Bibliográficas}

Ahsen, A. (1972). Eidetic parents test and analysis. New York: Brandon House.

American Psychiatric Association (2003). Diagnostic and Statistical Manual of Mental Disorders: DSM-IV-TR. Barcelona, España: Masson. 
Beck, AT., Weissman, A., Lester D. \& Trexler L., (1974). The measurement of pessimism: The hopelessness Scale. Consult. J.Clin. Psychol. 42(6), 861-865.

Berne, E (1974). ¿Qué dice usted después de decir hola? Barcelona, España: Grijalbo.

Cheavens, J.S., Feldman, D.S., Gum, A., Michael, S.T. \& Snyder, C.R. (2006). Hope Theory in a community simple: a pilot investigation. Social Indicators Research. 77, 61-78.

Friedberg, F. (2003) La técnica de los movimientos oculares. Bilbao, España: Desclèe de Brouwer.

Gimeno-Bayón, A. (1985). Esculpiendo mis emociones. Revista de Psiquiatría Humanista, 11, 63-66.

Gimeno-Bayón, A. (1996). Comprendiendo cómo somos. Dimensiones de la personalidad.

Bilbao, España: Desclée de Brouwer.

Gimeno-Bayón, A. (2014). Psicopatología y psicoterapia de la fase de valoración ética. Revista de Psicoterapia, 25(97), 43-78. http://revistadepsicoterapia.com/psicopatologia-y-psicoterapia-valoracion-etica.html

Gimeno-Bayón, A. \& Rosal, R. (2001) Psicoterapia Integradora Humanista. Manual para el tratamiento de 33 problemas psicosensoriales, cognitivos y emocionales. Bilbao, España: Desclée de Brouwer.

Gimeno-Bayón, A. \& Rosal, R. (2012). Análisis transaccional para terapeutas. Vol. II. Tratamiento de los trastornos de la personalidad y algunos síndromes. Barcelona, España: Milenio.

Gimeno Bayón, A. \& Rosal, R. (2016). Psicoterapia Integradora Humanista. Volumen II. Manual para el tratamiento de 69 problemas que aparecen en distintos trastornos de la personalidad. Bilbao, España: Desclée de Brouwer.

Greenberg, L.S. (2000). Emociones: una guía interna. Bilbao, España: Desclée de Brouwer.

Greenberg, L.S., Rice, L. \& Elliot, R. (1996). Facilitando el cambio emocional: el proceso terapéutico punto por punto. Madrid, España: Paidós Ibérica.

Hubble, M. A., Duncan, B. L. \& Miller, S. D. (1999). The heart and soul of change: What works in therapy. Washington, DC: American Psychological Association.

Kohlberg, L. (1969) Stage and sequence: the cognitive-development approach to socialization. En D. Goslin (Ed.), Handbook of socialization. Theory and research (pp. 347-480). Chicago: Rand McNally

Larsen, D., Edey, W., \& LeMay, L. (2007). Understanding the role of hope in counselling: Exploring the intentional uses of hope. Counselling Psychology Quarterly, 20, 401-416.

Larsen, D. \& Stege, R. (2010a). Hope Focused Practices During Early Psychoterapy Sessions: Part I: Implicit Approaches. Journal of Psychoterapy Integration, 20(3); 271-292.

Larsen, D. \& Stege, R. (2010b). Hope Focused Practices During Early Psychoterapy Sessions: Part II: Explicit Approaches. Journal of Psychoterapy Integration, 20(3); 293-311.

Levitsky, A. \& Perls, F.S. (1973). Teoría y práctica de la psicoterapia gestáltica (pp.144-152). Buenos Aires, Argentina: Amorrortu.

Lizeretti, N.P. \& Gimeno-Bayón, A. (2014). Inteligencia emocional y valores éticos. Revista de Psicoterapia, 25(97); 79-104. http://revistadepsicoterapia.com/inteligencia-emocional-y-valores-eticos.html

Millon, T. \& Everly, G.S. (1994). La personalidad y sus trastornos. Barcelona, España: Martínez Roca.

Moiso, C. (1983).Teoría psicológica y neurofisiológica de los sentimientos y proceso terapéutico. Seminario dictado en Barcelona (Noviembre 1983).

O’Hearne, L.P. (1977). Contes des fées et redécisions. Actualités en Analyse Transactionelle, 1(2), 271-276.

Real Academia Española. (s.f.). Diccionario de la lengua española (23ª Ed., 2014). Madrid, España. Recuperado de http://dle.rae.es/?id=GYjXr3Q.

Rosal, R. (2003) ¿Qué nos humaniza? ¿Qué nos deshumaniza? Bilbao, España: Desclée de Brouwer.

Rosal, R. (2013). El poder psicoterapéutico de la actividad imaginaria y su fundamentación cientifica. Lleida, España: Milenio.

Rosal, R. (2014). Problemas sensoriales y emocionales que obstaculizan la vivencia de los valores éticos. Revista de Psicoterapia, 25(97). 1-42.http://revistadepsicoterapia.com/problemas-sensoriales-y-emocionales.html

Snyder, C. R.; Harris, Cheri; Anderson, John R.; Holleran, Sharon A.; Irving, Lori M.; Sigmon, Sandra T,... Harney, Pat. (1991). The will and the ways: Development and validation of an individual-differences measure of hope. Journal of Personality and Social Psychology, 60, 570-585.

Snyder, C. R., Rand, K. L. \& Sigmon, D. R. (2002). Hope theory: A member of the positive psychology family. Handbook of positive psychology (pp. 257-276). New York: Oxford University Press.

Stevens, J.O. (1976). El darse cuenta: sentir, imaginar y vivenciar. Santiago de Chile, Chile: Cuatro Vientos. 